\title{
ICF: The World Academy of Structural Integrity - retrospective and prospective
}

\author{
D.M.R. Taplin ${ }^{\mathrm{a}, *, * *}$ and Ashok Saxena ${ }^{\mathrm{b}, * * *}$ \\ ${ }^{a}$ School of Engineering and Applied Science, Aston University, Birmingham, UK \\ ${ }^{\mathrm{b}}$ Department of Mechanical Engineering, College of Engineering, University of Arkansas, Fayetteville, \\ AR, USA
}

Received 2 August 2011

Accepted 4 August 2011

\begin{abstract}
The International Congress on Fracture (ICF) was created through the vision of Takeo Yokobori in Sendai, Japan in 1965. The primary emphasis of Yokobori was to join the micro- and macro-mechanics aspects of fracture research. The outstanding growth of ICF demonstrates that the founding effort was the right approach to the right topic at the right time. The "ICF Brand" is now recognised around the world as one of the leading international societies in the broad field of structural integrity, fracture, fatigue, creep, corrosion and reliability - from biological to geophysical materials, from nano to macro scales, from basic science to practical engineering and technology and systems modelling. In this paper we trace the history of the development of fracture research and of ICF via the many threads of, for example, the E24/E9 committees of ASTM; the US Committee on Ship Steel linked to work on the Liberty Ships in the Engineering Laboratories, Cambridge, England; early work in Germany, France and Japan - culminating in the MIT Swampscott Fracture Conference of 1959 ("ICF0"), the pre-cursor to ICF1 in Sendai in 1965. We then examine the impact of the ICF quadrennial series of international fracture conferences from ICF1 through to ICF12 in Ottawa, Canada in 2009. The key is the original research presented in some 5000 scientific papers and to be made available online on the new ICF website (www.icf-wasi.org). Finally we examine the evolution of ICF since 2009 towards ICF13 in Beijing, China in 2013 (www.ICF13.org) and forward for the next decade and beyond.
\end{abstract}

\section{Introduction}

The International Congress on Fracture (ICF) was founded through the comprehensive vision on the fracturing of materials of Takeo Yokobori in Sendai Japan in November 1965; and, in Sendai again in October 2010, we celebrated the 90th Birthday of Takeo Yokobori in a special ICF interquadrennial conference. The legend of Takeo Yokobori provides the foundation spirit of ICF and this now internationally recognised "brand" as the world leader. As Teruo Kishi remarked in Sendai at the celebration banquet "ICF \& Takeo Yokobori are synonymously revered, in Japan and world-wide". Takeo Yokobori graciously accepted our accolades and the newly created title of "Founder-President Emeritus" and endorsed the evolution of ICF as "ICF: The World Academy of Structural Integrity".

\footnotetext{
*Corresponding author. E-mail: coliemore@ hotmail.com.

${ }^{* *}$ CEO and President Emeritus ICF-WASI; Fellow of the Cooperative Research Centre for Infrastructure and Engineering Asset Management, Brisbane, Australia QLD 4001; and Visiting Professor of Structural Integrity, School of Engineering and Applied Science, Aston University, Birmingham, UK.

*** Vice-President ICF-WASI; Department of Mechanical Engineering, College of Engineering, University of Arkansas, Fayetteville, AR 72701, USA.
} 
ICF sprang from various threads of activity in the 1950s, mainly in the USA after the appearance of the pioneering ASM book "Fracturing of Metals", which important reference included among other valuable contributions two seminal papers: the first on the micro-mechanics aspects of fracture initiation by Clarence Zener; the second on the energetics of dynamic fracturing of pre-cracked materials by George Irwin.

We could delve back to Leonardo de Vinci and Galileo Galilei during the Italian Renaissance or to early work in Germany in the 19th century but serious modern work might be said to have begun through Charles Inglis in 1913 in England and especially later work by Alan Griffith in Liverpool and at the Royal Aircraft Establishment, England, published by the Royal Society and importantly presented at the IUTAM Conference in Delft in 1924. However, the immediate precursor to ICF1 was an MIT International Fracture Conference at Swampscott in 1959 which was supported by the National Science Foundation, the Air Force Office of Scientific Research, the Office of Naval Research and the Ship Structure Committee of the National Academy of Sciences-National Research Council. The MIT Swampscott Committee comprised Ben Averbach (MIT, Chairman), R.J. Charles (GE Research), A.H. Cottrell (Cambridge, England), J.R. Low Jr. (GE Research), T.L. Smith (CalTech) and D.K. Felbeck (Secretary, NAS-NRC).

The Swampscott Conference was materials/micro-mechanisms oriented. The names of the speakers were wide-ranging including Irwin, Orowan, Petch, Cottrell, McClintock, Barrett, Cohen, Crussard, Friedel, Zener, McEvily, Parker, Gilman, redolent of a bygone age perhaps yet the papers published resonate today. Swampscott was followed in 1962 by an International Fracture Conference in Seattle this was fracture mechanics oriented. Then various meetings were held at MIT to which Takeo Yokobori was invited and the suggestion was made via Ben Averbach for Takeo Yokobori to organise in Japan an international fracture conference with a wide-ranging scope covering mechanics and micro-mechanisms within the internal structure of polycrystalline materials and extending to the macro-mechanics of largescale engineering structures.

The key meeting was at MIT on November 6, 1961 with Ben Averbach in the Chair and involving Frank McClintock, Ali Argon, Egon Orowan, Den Hartog, John Chipman, Morris Cohen and Takeo Yokobori. This led to the formation of an "Interim International Fracture Conference Committee" of Takeo Yokobori (Chairman), Ben Averbach, Alan Cottrell, Max Williams, Jacques Friedel, Alan Head, Peter Haasen, Norman Petch, S.N. Zhurkov, with Tadashi Kawasaki and Jerry Swedlow as Joint Secretaries. With then "ICF1" organised by the "Japanese Society for Strength \& Fracture of Materials" (JSSFM) which is still the link organisation for ICF in Japan. At "ICF1" W.N. Findley of Brown University was the official representative of ASTM a key sponsor.

ICF1 was every bit the success that was envisaged in November 1961 at MIT and it was decided in Sendai in November 1965 to arrange for a second international conference in England (ICF2) especially in view of the work in Cambridge (G.I. Taylor, Constance Tipper, Alan Cottrell, Tony Kelly), at the National Physical Laboratory (Norman Allen, Donald Mclean) and within UKAEA (Roy Nichols) and nuclear reactor safe design, again incorporating research emphases spanning micro- to macro-scale researches dedicated to fracture prevention, control and safe design.

It was only at ICF2 in Brighton, England that ICF was in fact formally founded in April 1969 with Roy Nichols as ICF2 Executive Chairman and Takeo Yokobori as ICF President. Thereafter ICF3 was held in Munich, Germany in April 1973 with Albert Kochendoerfer as ICF3 Executive Chairman. In Munich Ben Averbach became the second ICF President succeeding Takeo Yokobori and ICF Council appointed David Taplin as ICF4 Executive Chairman with ICF4 in Waterloo, Canada, in June 1977 supported strongly by the USA in a joint programme. At ICF4 Roy Nichols became ICF President. ICF5 
was then hosted by France in Cannes in April 1981 with Dominique Francois as the ICF5 Executive Chairman and subsequently David Taplin was elected as the fourth ICF President.

The period of 1960s and 1970s also saw the rise of the Committee E-24 on Fracture Mechanics within ASTM and the development of early standards for test methods for measuring fracture toughness and fatigue crack growth behaviour of metals. The Committee E09 on Fatigue also emerged as a powerful force within ASTM to tackle issues associated with fatigue fractures. These two committees merged under the umbrella of a single committee on Fatigue and Fracture Mechanics, E08 in 1993, which continues to this day as an important source of standard test methods relating to fracture.

The same period also saw the emergence of the National Fracture Mechanics Symposium series conducted annually with roots in Lehigh University under the leadership of Paul Paris, George Sih and George Irwin but also including several younger researchers such as James Rice and John Hutchinson, James Begley and John Landes, Richard Hertzberg, Robert P. Wei, Robert Bucci and others all of whom received their fracture education at Lehigh University. Other contributors to these series included Edward T. Wessel, James Newman, Bill Brown, John Srawley, John Shannon, John Barsom and William G. Clark Jr., Karl-Heinz Schwalbe, Ashok Saxena, Hugo Ernst, Donald McCabe, Jerry Swedlow and John Gudas, Ravi Chona. The proceedings of these conferences were published in now a legendary series of Special Technical Publications (the STPs) that are a source of several seminal contributions in fracture research. This series of conferences has continued to this date in cooperation with the European Structural Integrity Society (ESIS) biennially with ASTM and ESIS rotating their respective conferences each year; that is, one year in Europe sponsored by ESIS and the other in the USA sponsored by ASTM also now in collaboration with ICF-WASI as an Interquadrennial Conference, the first being in May 2011 in Anaheim, CA, USA.

Dominique Francois, who in 1985 following ICF6 was elected as the fifth ICF President, had in 1976 established at Compiegne EGF, the European Group on Fracture and the First European Conference on Fracture. EGF later became "The European Structural Integrity Society" and the ECF series continues biennially so that in 2010 ECF18 was held in Dresden, Germany as also an ICF Interquadrennial Conference.

It was at the time following ICF4 that an early effort was made to create a wider collaboration which later can be perhaps seen to have become the ICF-WASI of today. Through the publication of the ICF4 Proceedings with Pergamon (later Elsevier), continuing indeed to ICF10 in Hawaii, USA in 2001, a Book Series was established with David Taplin as General Editor which encompassed ICF, ICM, ICSMA, ICCM and other conference proceedings and monographs in the broad field of Strength and Fracture of Materials and Structures. With the progressive changes in publishing accompanying the development of the internet and online/CD proceedings, this collaboration dissipated. Attempts to develop ICF were also considered in regard to possible enhanced links with EGF/ESIS during the ESIS Presidency of Emmanuel Gdoutos but this possible development requires further negotiation in future quadrennia.

ASTM through the E08 Committee on Fracture and Fatigue acts as the link in the USA with ICF (E08 Chairman Ravi Chona) and we have agreed an ICF/ASTM MoU for further developments with ASTM International (www.astm.org). The Canadian Fracture Group (CFRC) was set up by David Taplin and Don Mills in 1976 linked to ICF4 and continues actively today with Bill Tyson as Chairman and regular National Conferences. The Italian Fracture Group is very active with Francesco Iacoviello as Chairman and an ICF/IGF MoU has been signed which covers also the IGF hosting of a new ICF website. Similarly has been established the Greek Fracture Group (GGF: Chairman Emmanuel Gdoutos), The Far-East Fracture Group (FEFG: Chairman Ti-yong Zhang) and The Japanese Fracture Group (JSSFM: Chairman Teruo Kishi). The Russian Fracture Group (RFG) has organised several ICF IQ's in Moscow led by 
Robert Goldstein. In the UK the UK Royal Society through IUTAM was the original link to ICF and the UK has also had links of ICF with IoM3 (Institute of Materials Minerals and Mining www.iom3.org) and UKFESI (UK Forum on Engineering Structural Integrity).

In Germany DVM (Deutscher Verband fur Materialforschung-und-prufung - The German Association for Materials Research and Testing www.DVM-berlin.de) acts as the umbrella for the German Fracture Group and this collaboration is being established more formally with an ICF-WASI/DVM MoU including links with the VHCF series (Very High Cycle Fatigue) via Claude Bathias and Christina Berger and the LCF series. There are also links being formalised with France, Portugal and Spain and the International Journal of Structural Integrity via MoU's. The Australian Fracture Group has been active since 1971 and was involved in organising ICF9 in Sydney 1997. We hope for a series of such MoUs to regularise all such national and regional links with ICF as a comprehensive network.

The early history of ICF might be viewed as the period ICF1-ICF5, 1965-1981. The second era might be viewed as ICF6 December 1984 in New Delhi, India, through to ICF13 in May 2013 in Beijing, China. ICF7 in Houston, Texas in 1989 was remarkable in achieving an enhanced unity for the first time amongst the disparate fracture groups in the USA. ICF8 was originally to be in the USSR and was also historical as this was achieved under great pressure through the dissociation of the USSR and in the new independent Republic of the Ukraine. Australia had been endeavouring to host an ICF Quadrennial for some years and had bid in 1984, 1989 and 1993 winning in 1993 to then host ICF9 in Sydney in 1997 very successfully. ICF10 was a special joint hosting experiment between USA and Japan and held in Hawaii, USA, with Joint Executive Chairmen from the USA and Japan. ICF11 was an especially successful conference in Turin, Italy in 2005 with Alberto Carpinteri as ICF11 Executive Chairman. ICF12 then returned to Canada and was hosted in Ottawa in 2009 with Mimoun Elboujdaini as ICF12 Executive Chairman.

During the ICF Presidency of David Taplin, a guideline for rotation of the quadrennial conferences within the three overall world geographic regions was adopted: Europe/Africa, Asia/Pacific and Americas, and this has been essentially followed to benefit, bearing in mind that the decision on the location of Quadrennial Conferences is taken by ICF Council via secret balloting. To provide for longer than the 3-4 years of necessary planning with also now the institution of a strict $\mathrm{MoU}$ process for quadrennials introduced at ICF Council in 2005 in Turin, ICF Council now decides provisionally on the location of the quadrennial on an eight year cycle. So that at ICF13 a decision will be made on ICF15 in 2021 (probably in the Americas) and affirm the decision already taken on ICF14 in Greece in 2017 as also (akin to ICF10) a joint hosting by Greece and the UK. The joint hosting of Quadrennials and Interquadrennials is encouraged to enhance collaborations. Already early discussions on the location of ICF16 in 2025 and ICF17 in 2029 have begun and regarding a more closely co-ordinated scheme for Interquadrennials.

Indeed, the most important era for ICF must surely be the period ahead from 2013 onwards and it is with the "prospective" for ICF on which this paper mainly focuses. This paper is designed as simply an Introductory work as a basis for ongoing discussion on the new ICF website (www.icf-wasi.org) in the "Strategic/History" section via Francesco Iacoviello. Within this section will also be logged the various ICF quadrennial conference reports to provide an ongoing comprehensive picture of ICF in a global context. ICF has matured fundamentally through the original work presented, the Honour Lectures especially and in overcoming several historic difficulties. These include issues related to the processes associated with the ending of apartheid in South Africa and its effect upon ICF6 in New Delhi, India with Palle Ramo Rao as ICF6 Executive Chairman; the developments from the dissociation of the USSR from $~ 1990$ and its effect on ICF8 in Kiev, Ukraine with Volodymir Panasyuk as ICF8 Executive 
Chairman and Palle Rama Rao as ICF President; the changes consequent upon the Arab Spring and Interquadrennials arranged in Egypt and Libya as well as the massive growth of China as a new leading world power and therefore the special place of ICF13 (www.ICF13.org) in Beijing in May 2013.

\section{Brief history of fracture research}

As early as 1855, a German scientist, August Wohler, recognized fatigue as the cause of failures in railroad axles and related the number of cycles to failure with stress amplitude [1]. This correlation later became popularly known as the Wohler Diagram and an understanding evolved linking stress concentrations near surfaces and their role in initiating fatigue failures. Fifty years later, during the period of 1901 to 1905 a French Scientist, Georges Augustin Albert Charpy developed an impact load test that bears his name, the Charpy Test. The development of this test led to the understanding of brittle fracture in steels by experimentally demonstrating the plasticity-constraining effects of notches in promoting brittle fracture.

In 1913, C.E. Inglis [2] proposed the concept of stress concentration at elliptical holes, thus providing a theoretical basis for why fractures emanate from cracks, holes or other defects. Soon after, A.A. Griffith [3] combined Inglis' derivation with his hypothesis about energy exchanges that take place during fracture and derived the concept of critical crack size necessary for brittle fracture. Griffith derived theoretically an inverse relationship between fracture stress and the square root of crack size and was able to experimentally demonstrate that this relationship was obeyed for brittle materials such as glass. However, attempts at applying this theory to metals did not meet with success.

The next significant development in fracture mechanics did not occur until 1948. Zener [4], as mentioned above, introduced the model of atomic scale fracturing caused by dislocation pile-ups. Motivated by trying to understand fracture in ship hulls, G.R. Irwin [5] and E. Orowan [6] independently proposed modifications to Griffith's theory to account for plastic energy that is dissipated during the fracture process in metals. This modification made it possible to apply Griffith's theory to metals. In the same year, N.F. Mott [7] published his paper which extended Griffith's analysis by taking kinetic energy into account. He was able to derive expressions for predicting crack speeds. This paper is widely accepted as the first piece of significant research in the field that is now known as dynamic fracture mechanics.

In the subsequent years, the efforts focused on generalizing the modified Griffith's approach to other geometries more suited for engineering applications. In 1956, G.R. Irwin [8] proposed the concept of energy release rate or the crack extension force, which successfully met this criterion. In 1939, H.M. Westergaard [9] published the results of his analysis demonstrating that the stresses near the tips of cracks in elastic bodies varied as a function of $l / \sqrt{r}$, where $r=$ distance from the crack tip. The significance of this work was not realized until much later when Irwin published another landmark piece of research [10] in which he was able to use the Westergaard approach to show that the amplitude of stresses and displacements in front of crack tips in elastic solids can be expressed by a single parameter, now widely known as the stress intensity parameter, $K$. Irwin further demonstrated that $K$ can be uniquely related to the strain energy release rate, thus making the very important connection between the stress and energy based approaches for predicting fracture. Shortly after that, M.L. Williams [11] used a different technique and proposed a more complete description of the crack tip stress fields. However, in the region of the crack tip where fracture processes occur, Williams' results essentially agreed with those of Irwin's lending even more credibility to Irwin's theories on fracture in engineering metals. 


\section{Developments in linear elastic fracture mechanics}

In the mid-1950s, fracture mechanics research received a much needed credibility boost in the aftermath of Comet aircraft failures and the efforts by Boeing to ensure that similar failures do not plague their new line of planes called the Boeing 707. The aircraft industry, which was using high strength materials such as the precipitate hardened $\mathrm{Al}$ alloys and high strength steels, realized the merits of the field of Fracture Mechanics and joined forces with the US Navy which had already accepted the importance of fracture mechanics research in the aftermath of liberty ship failures during World War II. Engineers working in Boeing led by Paul C. Paris joined forces with those at the Naval Research Laboratory under the leadership of George Irwin to understand brittle fracture in metallic components. The period of the early 1960s saw the concept of plane strain fracture toughness, $K_{\mathrm{IC}}$, evolve and become widely accepted. The crack tip opening displacement (CTOD) concept originated in the UK through the efforts of A.A. Wells at about the same time. The close relationship between CTOD and the $K$-based approaches has always been recognized and even fostered a close personal relationship between Alan Wells and George Irwin. The CTOD approach was used more frequently in Europe while the $K$-based approach was more popular in the USA with both sides recognizing the unique relationship between the two through an analysis credited to Joseph Kies and George Irwin.

In 1961, Paul C. Paris and co-workers [12] first proposed the relationship between fatigue crack growth rate and the cyclic stress intensity parameter, $\Delta K$. Although this approach met with initial resistance, it ultimately became universally accepted and was popularly labeled as the "Paris-Law". This development also motivated others to establish the relationship between sub-critical crack growth and the stress intensity parameter under the conditions of stress corrosion. The nineteen sixties and seventies were decades where linear elastic fracture mechanics (LEFM) flourished and was firmly established as an approach to tackle fracture problems in several industries. This period also saw the adoption of retirement-for-cause maintenance philosophy and the defect tolerance design approach, both relying heavily on Fracture Mechanics and thus providing the impetus for its further development.

The use of Fracture Mechanics in structural integrity assurance was also enabled through the pioneering work of several people on estimating stress intensity parameters for complex geometries and loading conditions. Fracture Mechanics researchers were quick to adopt finite element analysis as a tool, which was just emerging at the time, for estimating stress intensity parameters. The early work of Paul Paris, George Sih, George Irwin and Hiroshi Tada as well as that of John Srawley and William Brown at NASA was extended to 3-D cracks by J.C. Newman and I.S. Raju also working at NASA. By the mid-nineteen seventies the discipline of linear elastic fracture mechanics (LEFM) was firmly established and papers relating to that were presented at several major conferences including the ICF conferences that were also established by then.

By then, several major corporations and National Laboratories supporting heavy industry were involved with Fracture Mechanics research and the field was flourishing with new developments taking place at a very fast pace. All major technical societies, in addition to ASTM, in the US such as ASME, ASM International, MRS and TMS as well as others had significant activities in the field of Fracture Mechanics at their regular meetings. The links between ASTM and ICF were strong because ICF, right from its beginnings in the early nineteen sixties, included Fracture Mechanics researchers such as Max Williams, George Irwin, Ed Wessel, Alan Wells, Paul Paris and Jerry Swedlow amongst its early founders.

By the end of the decade of 1960s it was also fully understood that the use of LEFM is limited to conditions when linear-elastic conditions dominate the behaviour of the cracked body. As early as in 
mid to late nineteen sixties, researchers were already looking for ways to extend Fracture Mechanics into the elastic-plastic and fully plastic regimes. To put it in perspective, the early Griffith theories did not admit any plastic deformation and were therefore not suited for metals. LEFM extended the approach to include small scale yielding thus extending its use to brittle metals in which fracture is accompanied by limited plastic deformation. Therefore, extending the Fracture Mechanics approach to include substantial plasticity was the next logical step in its evolution.

In the early 1970s, there was also an active group working in Cambridge University in England looking at interactions between microstructure and fracture. Many important results from this work were motivated by John Knott [13]. The most notable of that work is the RKR (named after Robert Ritchie, John Knott and visiting researcher James R. Rice) model that explained cleavage fracture triggered by non-metallic inclusions in the vicinity of the crack tip. This theory was able to provide a phenomenological explanation for why there was so much scatter in the plane strain fracture toughness values of steel in the ductile-to-brittle transition region leading later on to a statistical approach to treating the scatter because of the stochastic nature of the inclusion distribution [14]. This explanation was instrumental in establishing LEFM even more firmly because it laid rest to the discussions about unusual scatter in the toughness values expressed as $K_{\mathrm{IC}}$ in the transition region for structural steels. The microstructural connection extended to cover the crystal-orientation-dependent Cottrell mechanism and a related RKR influence of particle size and grain size on the transition to brittle cleavage typically occurring at the Charpy upper shelf energy level, was later elaborated at the EGF9 Conference in Germany [15].

\section{Developments in elastic-plastic fracture mechanics}

The nuclear power industry was gaining prominence during the nineteen sixties and several ambitious projects were initiated to harness nuclear power safely and more economically. The materials used in the power industry were ductile steels in which fracture was invariably accompanied by extensive plastic deformation, at least when attempts were made to measure the $K_{\mathrm{IC}}$ of these materials using laboratory-size specimens. It was clear that if fracture mechanics were to be applied successfully in these applications, the analytical theory had to be extended to include fracture under elastic-plastic and fully-plastic conditions.

In 1968, three papers of considerable significance to the development of elastic-plastic fracture mechanics appeared. Rice [16] idealized plastic deformation as a nonlinear elastic phenomenon for mathematical purposes and was able to generalize the concept of energy release rate for such materials. He expressed this in the terms of a path-independent contour integral that he called J. Rice noted that this integral could also be derived from one of several conservation integrals proposed earlier by Eshelby [17]. Hutchinson [18] and Rice and Rosengren [19] in the same year derived the relationships between $J$-integral and the crack tip stress, strain and displacement fields in a manner similar to how crack tip fields are related to $K$ under linear-elastic conditions. Since $J$ was derived for nonlinear elastic materials, it was considered to have severe limitations for characterizing fracture in elastic-plastic materials, in particular metals in which crack growth is accompanied by local unloading in the process zone. On the other hand, Wells [20] had already demonstrated considerable success with CTOD as a fracture parameter even under conditions of significant plasticity.

In the late nineteen sixties, Edward T. Wessel, who was one of the pioneers in the development of the ASTM Standard E-399 for measurement of $K_{\mathrm{IC}}$, assembled a group at Westinghouse Electric Corporation's Research and Development Center in Pittsburgh to tackle the difficult problem of fracture under 
elastic-plastic conditions. Wessel had given the responsibility of this difficult task to two of his very young engineers by the names of J.A. Begley and J.D. Landes. Begley and Landes proceeded to apply $J$-integral for characterizing the initiation of ductile fracture in spite of criticism from the mechanics community. At the time they felt that if their attempts to apply $J$ were unsuccessful, they might be able to find another fracture criterion; they received lots of encouragement from Paul Paris and George Irwin in their pursuits. In 1972, Landes and Begley [21,22] published the results of their first study on the use of $J$ to predict the initiation of fracture under elastic-plastic conditions.

Following these studies, the field of elastic-plastic fracture mechanics progressed rapidly with continued efforts of Landes and Begley but also due to some land-mark work of C.F. Shih [23] and by Hutchinson and Paris [24]. The latter two pieces of work provided a rigorous theoretical justification for characterizing stable crack growth using the $J$-integral at least for small amounts of stable crack growth. In the late nineteen seventies, Paul C. Paris and co-workers A. Zahoor and Hugo Ernst [25] developed the tearing modulus concept for predicting instability following ductile crack growth. About the same time, or actually a little earlier, Dowling and Begley [26] proposed the use of the cyclic $J$-integral for characterizing fatigue crack growth under elastic-plastic and fully-plastic conditions. In the subsequent years, much progress occurred in the development of test methods using the $J$-integral approach from the efforts of ASTM and in the development of methods for estimating $J$-integral, making elastic-plastic fracture mechanics a viable engineering tool in structural integrity assessments.

\section{Developments in time-dependent fracture mechanics}

In the early to mid-seventies, efforts had already begun to extend the concepts of fracture mechanics to crack growth under creep conditions. Some of the early pioneers included Siverns and Price [27] and L.A. James [28]. Their efforts were directed at extending the use of $K$ for creep and creep-fatigue crack growth. Since the crack tip stress fields are dependent also on time, the uniqueness between the crack tip stress field and $K$ can no longer assured; thus, these early efforts were not successful in the case of creep crack growth but were successful in characterizing creep-fatigue crack growth if smallscale creep conditions could be maintained and the loading waveform and time period could be held as constant. In 1976, Landes and Begley [29] and Nikbin, Webster and Turner [30] independently proposed the use of a $J$-like integral $\left(C^{*}\right)$ for characterizing creep crack growth. Subsequent experimental work of Taira and co-workers in Japan [31] and Saxena [32] in the US confirmed the validity of $C^{*}$ for characterizing creep crack growth. The primary limitation of $C^{*}$ was that it applied only to extensive secondary creep conditions. Ohji, Ogura and Kubo [33], Riedel and Rice [34], and McClintock and Bassani [35] formulated the problem of small-scale creep which was used subsequently by Saxena [36] to define the $C_{t}$ parameter which can be used to characterize creep crack growth under conditions ranging from small-scale to extensive creep. Next, formulations of $C_{t}$ were provided which account for cyclic loading [37] and also primary creep deformation [38,39]. In 1993, ASTM published a standard method, E-1457, for characterizing creep crack growth and in 2010 a yet another standard method for measuring creep-fatigue crack growth in metals, E-2760.

\section{Current research in fracture mechanics}

Although much progress has occurred in fracture mechanics over the past 60 years, it still remains an active field of research. Some of the current topics of research are fracture in inhomogeneous and 
anisotropic materials such as composites, effects of constraint on fracture toughness, creep and creepfatigue crack growth in creep-brittle materials, crack growth and fracture in weldments, and growth of small cracks and fracture under the conditions of mixed-mode loading. Another limitation of the current capabilities of fracture mechanics is its relatively weak connection with damage mechanisms at the crack tip. While use of global parameters such as $K, J, C^{*}, C_{t}$, etc. are very useful for predicting crack growth and fracture in engineering components, they do little for advancing the fundamental understanding of the material's resistance to crack growth and fracture. With advances in computer technology and also in experimental techniques for observing fracture mechanisms, this area of research is poised for significant gains especially in applications in new arenas such as biomedical and geophysical as well as in systems modeling for Infrastructure and Engineering Asset Management.

\section{Fracture micro-mechanisms and the Yokobori interdisciplinary micro-macro vision}

Physical metallurgy provided the core foundation for research on understanding the micromechanisms of fracture especially via for example Alan Cottrell and dislocation theory in the 1950s. The vision of Takeo Yokobori was to combine the macro "Fracture Mechanics" approach of theoretical and applied mechanics with the "Fracture Micromechanisms" approach of solid state physics and physical metallurgy in an interdisciplinary manner within the ICF mission.

A particular focus for Yokobori even from the 1940s was on creep fracture and this was reviewed in a paper twenty years ago as "Yokobori \& the Creep Fracture Story" for his Seventieth Birthday Festschrift [40]. Three key references by Yokobori and his team in Sendai address this vision comprehensively [4143] with a holistic/systems approach to the strength and fracture of materials co-existing with the macro and micro approaches.

John Knott succeeded Alan Cottrell as the leading fracture researcher at Cambridge and built the "Knott Group" arguably the leading international group in fracture micromechanisms also addressing the micro/macro interface as in Knott's ICF4 Plenary. This work has continued via the "Ritchie Group" at UC Berkeley (www.lbl.gov/ritchie/) one of Knott's prominent former research students whose research in micromechanisms in a range of new materials including biological has extended the scope of our discipline.

The (first) Opening ICF Honour Lecture at ICF4 by Mike Ashby and the (first) ICF Closing Honour Lecture at ICF4 by Bruce Bilby were important in this regard with the overall interdisciplinary mix which was accomplished at ICF4 in 1977 in Canada and the broadening of research into biological and biomedical areas and into issues of "Fracture \& Society" through a published interview with Alan Cottrell. These ideas of star-billings of Honour Lecturers and wide-ranging forums incorporating explorations of societal/political decision-making in an ever changing planet - especially with climate change, energy, transportation, resources challenges - have since become identifying aspects of the work of ICF-WASI especially at the quadrennial conferences.

Building on the early creep fracture research of Yokobori in the 1940s and 1950s much work on high temperature fracture was presented at the various ICF Quadrennials including work by Lou Coffin and Stan Manson at ICF1. Much of this work was concerned with understanding the micro-mechanisms of intergranular creep and fatigue fracture. Including work on environmental synergisms and fracture mapping at high temperatures [44-46]. The CDM approach (Continuum Damage Mechanics) was applied to creep fracture by Ashby and Dyson in their ICF6 Plenary [47] building from earlier creep fracture work of Taplin, Dyson and McLean in their ICF4 Plenary. Dyson has worked successfully on this topic 
[48] and the current state-of-the-art is presented in a 2009 paper [49]. For more than forty years fracture mechanics testing techniques have been applied to the study of time-dependent aqueous stress corrosion crack propagation in metals [50] and glasses [51], together with studies of hydrogen-assisted crack propagation in steels [52]. The hydrogen tests are relevant to the cracking of pipeline steel [53].

Much more needs to be written about the historical development of both the micromechanisms and mechanics (macro) aspects of the "ICF Story" as discussed below. This includes the origins and developments of the application of structural integrity ideas in ever-widening arenas of electronic/microprocessor reliability, natural/biological/biomedical, geophysical and infrastructure systems modelling.

\section{The ICF website and the "strategic/history" section}

An early draft of this present paper was distributed amongst some key members of the ICF community for comments and this created a very lively debate which ICF has decided should be developed in a more formal manner at ICF13 and through a new section of the ICF: WASI website. This is imagined as a blog-type section with contributions from senior researchers who have a long perspective from USA, UK, France, Germany, Japan, Italy, India, Canada, Australia, Russia, Scandinavia, China and elsewhere. The various available ICF Quadrennial Conference Reports (the first was the "ICF4 Report" through to the "ICF12 Report" where available) will also be included for as complete an archival record of the evolution of ICF. The core of the new ICF: WASI website will be a fully digitised and complete set of ICF Quadrennial Proceedings from ICF1 - ICF12 and onwards plus as many of the ICF Interquadrennial Proceedings as can also be assembled starting with ICF-IQ1 in Beijing in November 1983 and the ICF0 Proceedings from 1959 and other historical texts.

\section{Conclusions}

(1) We commemorate here with deepest condolences to all our friends and colleagues in Sendai and more widely in Japan the tragic consequences of the 2011 Tsunami. The whole ICF community has special associations with Sendai and at the ICF Executive Committee meeting in Anaheim, USA we stood in a Minute's Silence of respect and solidarity with our colleagues in Japan, the founding nation of ICF in Sendai.

(2) "The International Congress on Fracture: The World Academy of Structural Integrity" is now formally established (Anaheim, USA, May 2011) with an evolved "global brand" reflecting the new and widened remit of the original ICF encompassing "Structural Integrity" in its widest possible meaning as the discipline of our ever-changing community.

(3) To demonstrate and witness our evolution as a Congress, a Society we have become renamed as a "World Academy" with Academicians elected by Council every four years and Associates who comprise the whole company of delegates ongoing of the Quadrennial and Inter-quadrennial conferences over the decades (possibly as many as 10,000 members of the ICF-WASI community) in an encompassing and inclusive, democratic manner.

(4) We have in addition recognised as in other World Academies outstanding contributions to our discipline through a series of Gold (Yokobori, Irwin, Cottrell, Paris), Silver (Tipper) and Bronze (Presidential) Medals which are presented once every four years. As well we have similarly for a leading Academy created Emeritus positions in various categories. This is all in accord with all 
the new strategies and developments in particular during this quadrennium 2009-2013 under the visionary leadership of the ICF 2009-2013 President Alberto Carpinteri.

(5) Now we look forward aspirationally to the Thirteenth International Conference on Fracture ICF13 in Beijing May 2013, China for the first time under the new brand and banner of "The International Congress on Fracture: The World Academy of Structural Integrity". This is anticipated as a milestone in the history of ICF: WASI and also as a springboard for the next decade in ICF: WASI and beyond. The ICF13 Executive Chairman and ICF: WASI Senior Vice-President 20092013 Yu Shouwen leading the host team from CSTAM (The Chinese Society of Theoretical and Applied Mechanics) and seven other organisations in China with Tsinghua University.

(6) ICF: WASI is in a very healthy state in 2011 following the original conception as evidenced and demonstrated in the very lively and often passionate discussions in the ICF-WASI community today throughout our history - and through the enduring vision, aims and scope of our Constitution, Statutes and Bye-Laws, created through the leadership of our own now Legendary Takeo Yokobori.

\section{Acknowledgements}

We are indebted to several colleagues, in particular to Ronald Armstrong of the University of Maryland in College Park, USA, Brian Dyson latterly of Imperial College, London UK, Desmond Tromans of the University of British Columbia, Vancouver, Canada and Toshimitsu Yokobori of Tohoku University, Sendai, Japan for their suggestions and critique of the manuscript. We are also appreciative of comprehensive discussions with James Rice of Harvard University USA and Colin Atkinson of Imperial College UK regarding the genesis of the path independent integral methodology $(J)$ and important parallel work around 1967-1968 by amongst others Jock Eshelby and Bruce Bilby of Sheffield University UK, and Genady Cherapanov of Moscow University, Russia. We look forward to these very many lively discussions to develop at ICF13 and on the "Strategic History" section of the new ICF-WASI website.

\section{References}

[1] A. Wöhler, Theorie rechtekiger eiserner Brückenbalken mit Gitterwänden und mit Blechwänden, Zeitschrift für Bauwesen 5 (1855), 121-166 (in German).

[2] C.E. Inglis, Stresses in plate due to the presence of cracks and sharp comers, Transactions of the Institute of Naval Architects 55 (1913), 219-241.

[3] A.A. Griffith, The phenomena of rupture and flow in solids, Philosophical Transactions, Series A 221 (1920), 163-198.

[4] C. Zener, The micro-mechanism of fracture, in: Fracturing of Metals, American Society for Metals, Cleveland, OH, 1948, pp. 3-31.

[5] G.R. Irwin, Fracture dynamics, in: Fracturing of Metals, American Society for Metals, Cleveland, OH, 1948, pp. $147-166$.

[6] E. Orowan, Fracture and strength of solids, Reports on Progress in Physics XII (1948), 185-232.

[7] N.F. Mott, Fracture of metals: theoretical considerations, Engineering 165 (1948), 16-18.

[8] G.R. Irwin, Onset of fast crack propagation in high strength steel and aluminum alloys, in: Sagamore Research Conference Proceedings, Vol. 2, 1956, pp. 289-305.

[9] H.M. Westergaard, Bearing pressures and cracks, Journal of Applied Mechanics 6 (1939), 49-53.

[10] G.R. Irwin, Analysis of stresses and strains near the end of a crack traversing a plate, Journal of Applied Mechanics 24 (1957), 361-364.

[11] M.L. Williams, On the stress distribution at base of a stationary crack, Journal of Applied Mechanics 24 (1957), 109-114.

[12] P.C. Paris, M.P. Gomez and W.P. Anderson, A rational analytic theory of fatigue, The Trend in Engineering 13 (1961), 9-14.

[13] J.F. Knott, Fundamentals of Fracture Mechanics, Butterworths, London, 1973. 
[14] R.O. Ritchie, J.F. Knott and J.R. Rice, On the relationship between critical tensile stress and fracture toughness in mild steel, Journal of Mechanics and Physics of Solids 21 (1973), 395-410.

[15] J.P. Gudas, G.R. Irwin, R.W. Armstrong and X.J. Zhang, A model for transition fracture of low carbon ferritic steels, in: EGF9 Proceedings 1991, MEP, London, 1991, pp. 549-568.

[16] J.R. Rice, A path independent integral and the approximate analysis of strain concentration by notches and cracks, Journal of Applied Mechanics 35 (1968), 379-386.

[17] J.D. Eshelby, The continuum theory of lattice defects, Solid State Physics 3 (1956), 79-141.

[18] J.W. Hutchinson, Singular behavior at the end of a tensile crack tip in a hardening material, Journal of Mechanics and Physics of Solids 16 (1968), 13-31.

[19] J.R. Rice and G.F. Rosengren, Plane strain deformation near a crack tip in a power-law hardening material, Journal of Mechanics and Physics of Solids 16 (1968), 1-12.

[20] A.A. Wells, Unstable crack propagation in metals: cleavage and fast fracture, in: Proceedings of the Crack Propagation Symposium, Vol. 1, Cranfield, UK, 1961, Paper 84.

[21] J.A. Begley and J.D. Landes, The $J$-integral as a fracture criterion, in: Fracture Toughness, ASTM STP 514, American Society for Testing and Materials, 1972, pp. 1-23.

[22] J.D. Landes and J.A. Begley, The effects of specimen geometry on $J_{\text {IC }}$, in: Fracture Toughness, ASTM 514, American Society for Testing and Materials, 1972, pp. 24-39.

[23] C.F. Shih, Relationship between crack tip opening displacement for stationary and extending cracks, Journal of Mechanics and Physics of Solids 29 (1981), 305-326.

[24] J.W. Hutchinson and P.C. Paris, Stability analysis of $J$-controlled crack growth, in: Elastic-Plastic Fracture, ASTM STP 668, American Society for Testing and Materials, 1979, pp. 37-64.

[25] P.C. Paris, H. Tada, A. Zahoor and H. Ernst, The theory of instability of the tearing mode of elastic-plastic crack growth, in: Elastic-Plastic Fracture, ASTM STP 668, American Society for Testing and Materials, 1979, pp. 5-36.

[26] N.E. Dowling and J.A. Begley, Fatigue crack growth during gross plasticity and the J-integral, in: Mechanics of Crack Growth, ASTM STP 590, American Society for Testing and Materials, 1976, pp. 82-103.

[27] M.J. Siverns and A.T. Price, Crack propagation under creep conditions in quenched 2.25Cr-1Mo steel, International Journal of Fracture 9 (1973), 199-207.

[28] L.A. James, The effect of frequency upon the fatigue crack growth of type 304 stainless steel at 1000 F, in: Stress Analysis of Growth of Cracks, ASTM STP 513, American Society for Testing and Materials, 1972, pp. 218-229.

[29] J.D. Landes and J.A. Begley, A fracture mechanics approach to creep crack growth, in: Mechanics of Crack Growth, ASTM STP 590, American Society for Testing and Materials, 1976, pp. 128-148.

[30] K.M. Nikbin, G.A. Webster and C.E. Turner, Relevance of nonlinear fracture mechanics to creep cracking, in: Cracks and Fracture, ASTM STP 601, American Society for Testing and Materials, 1976, pp. 47-62.

[31] S. Taira, R. Ohtani and T. Komatsu, Application of $J$-integral to high temperature crack propagation, Transactions of ASME, Journal of Engineering Materials Technology 101, 1979, 163-167.

[32] A. Saxena, Evaluation of $C^{*}$ for characterization of creep crack growth behavior of 304 stainless-steer, in: Fracture Mechanics: Twelfth Conference, ASTM STP 700, American Society for Testing and Materials, 1980, pp. 131-151.

[33] K. Ohji, K. Ogura and S. Kubo, Stress-strain field and modified $J$-integral in the vicinity of the crack tip under transient creep conditions, Japan Society of Mechanical Engineers No. 790-13 (1979), 18-20 (in Japanese).

[34] H. Riedel and J.R. Rice, Tensile cracks in creeping solids, in: Fracture Mechanics: Twelfth Conference, ASTM STP 700, American Society for Testing and Materials, 1980, pp. 112-130.

[35] J.L. Bassani and F.A. McClintock, Creep relaxation of stress around a crack tip, International Journal of Solids and Structures 17 (1981), 79-89.

[36] A. Saxena, Creep crack growth under nonsteady-state conditions, in: Fracture Mechanics: Seventeenth Volume, ASTM STP 905, American Society for Testing and Materials, 1986, pp. 185-201.

[37] A. Saxena and B. Gieseke, Transients in elevated temperature crack growth, in: Proceedings of MECAMAT, International Seminar on High Temperature Fracture Mechanisms and Mechanics, EGF-6, 1987, pp. 19-36.

[38] H. Riedel, Creep deformation at crack tips in elastic-viscoplastic solids, Journal of Mechanics and Physics of Solids 29 (1981), 35-49.

[39] C.-P. Leung, D.L. McDowell and A. Saxena, Consideration of primary creep at a stationary crack tip: implications for the C, parameter, International Journal of Fracture 36 (1988), 275-289.

[40] D.M.R. Taplin and N.G. Taylor, Yokobori \& The Creep Fracture Story, Engineering Fracture Mechanics, Seventieth Birthday Memorial Volume, 1987.

[41] T. Yokobori, The Strength, Fracture and Fatigue of Materials, Noordhoff, Groningen, 1965, translated by J.D. Crisp.

[42] T. Yokobori, An Interdisciplinary Approach to Fracture and Strength of Solids, Noordhoff, Groningen, 1968, translated by J.D. Crisp.

[43] T. Yokobori, T. Iwadate, S. Konosu, A. Fuji and A.T. Yokobori Jr., The strength of materials and fractology, (innovatory development and application), edited by JSPS 129 committee (Chairman T. Yokobori), Sasaki Pub., 1999 (in Japanese). 
[44] M.F. Ashby, C. Gandhi and D.M.R. Taplin, Fracture maps, Acta Met. 25 (1978), 699-729.

[45] M.C. Pandey, B.F. Dyson and D.M.R. Taplin, Environmental synergisms during creep fracture, Proc. Roy. Soc. 393 (1984), $117-131$.

[46] M.C. Pandey, D.M.R. Taplin, M.F. Ashby and B.F. Dyson, Environment/creep interactions, Acta Met. 34 (1986), 22252233.

[47] M.F. Ashby and B.F. Dyson, Creep damage mechanics and micro-mechanisms, in: Proceedings ICF6, Vol. 1, Pergamon Press, 1984, pp. 3-30.

[48] B.F. Dyson, CDM in materials modelling and creep life prediction, J. Pressure Vessel. Technology 122 (2000), $281-296$.

[49] B.F. Dyson, Microstructure-based creep constitutive model, Materials Science and Technology 25 (2009), 213-220.

[50] B.F. Brown, A new stress-corrosion cracking test for high strength alloys, Materials Research Standards 6(3) (1966), $129-133$.

[51] S.M. Wiederhorn and L.H. Bolz, Stress corrosion and static fatigue of glass, Journal of the American Ceramic Society 53(10) (1970), 543-548.

[52] C.D. Beachem, A new model for hydrogen-assisted cracking (hydrogen "embrittlement"), Metallurgical Transactions 3 (1972), 437-451.

[53] H. Huang and W.J.D. Shaw, Cold work effects on sulfide stress cracking of pipeline steel exposed to sour environments, Corrosion Science 34(1) (1993), 61-78. 